\title{
Analisa Dan Perancangan Aplikasi Sistem Pelayanan Klinik Gigi (Studi Kasus: Dental Echo Clinic)
}

\author{
Dewi Lestari ${ }^{1}$, Inge Handriani ${ }^{2}$ \\ Program Studi Sistem Informasi, Fakultas Ilmu Komputer, Universitas Mercu Buana \\ Jl. Raya Meruya Selatan, Kembangan, Jakarta, 11650 \\ 41814120151@student.mercubuana.ac.id ${ }^{1}, \underline{\text { Inge.handriani@mercubuana.ac.id }{ }^{2}}$
}

\begin{abstract}
Dental Echo Clinic is a dental clinic located in Tangerang that is built to support health aspects and dental health services, Echo Dental Clinic has a conventionally running information system where patient administration still uses forms. To improve the performance of Dental Echo Clinic as one of the dental health services in Tangerang, it is proposed a design of a dental clinic service information system, hereinafter referred to as Analysis and Design of Dental Clinic Service System Applications. the purpose of this study is to improve the effectiveness of time in dental clinic services, improve the efficiency of the recording system in dental clinic services and to minimize losses due to misrepresentation of patient data. Development method for designing this dental clinic service system using the Waterfall method. The results in this study are expected to design this system can help increase the effectiveness of the time in the process of dental clinic services, help improve the efficiency of the recording system in the dental clinic quickly and strongly, and can help minimize the loss of occurrence of patient data recording errors. provide solutions to problems that arise when the existing system is still using conventional methods, designing this system facilitates the process of searching patient data, medical records, processing patient administration data, making reports and making it easier for officers to do their jobs.
\end{abstract}

Abstrak - Dental Echo Clinic merupakan Klinik gigi yang berada di Tangerang yang dibangun untuk menunjang aspek kesehatan dan pelayanan kesehatan gigi, Echo Dental Clinic memiliki sistem informasi yang berjalan secara konvensional dimana administrasi pasien masih menggunakan formulir. Untuk meningkatkan kinerja Dental Echo Clinic sebagai salah satu pelayanan kesehatan gigi di Tangerang, maka diusulkan sebuah Perancangan sistem informasi pelayanan klinik gigi yang selanjutnya disebut Analisa Dan Perancangan Aplikasi Sistem Pelayanan Klinik Gigi. tujuan penelitian ini untuk Meningkatkan efektivitas waktu dalam pelayanan klinik gigi, Meningkatkan efisiensi sistem pencatatan dalam pelayanan klinik gigi serta untuk Meminimalisir kerugian atas terjadinya kesalahaan pencatatan data pasien. Metode pengembangan untuk Perancangan sistem pelayanan klinik gigi ini menggunakan metode Waterfall. Hasil dalam penelitian ini diharapkan Perancangan sistem ini dapat membantu meningkatkan efektivitas waktu dalam proses pelayanan klinik gigi, membantu meningkatkan efisiensi sistem pencatatan dalam klinik gigi secara cepat dan akuat, serta dapat membantu meminimalisir kerugian atas terjadian kesalahan pencatatan data pasien. memberikan solusi dari permasalahan yang timbul ketika sistem yang ada masih menggunakan cara konvensional, perancangan sistem ini mempermudah proses pencarian data pasien, rekam medis, proses pengolahan data administrasi pasien, membuat laporan dan dapat memudahkan petugas dalam melakukan pekerjaannya.

Keywords — klinik, system informasi, waterfall, rekamedis.

\section{Pendahuluan}

Klinik adalah fasilitas pelayanan kesehatan yang menyelenggarakan pelayanan kesehatan perorangan yang menyediakan pelayanan medis dasar dan/atau spesialistik (Permenkes RI No. 9 Tahun 2014). Selain sebagai fasilitas pelayanan kesehatan, klinik juga berguna dalam membantu masyarakat sekitar untuk Observasi klinik terhadap kondisi tubuh masyarakat dapat dilakukan melalui pemeriksaan terhadap keluhan-keluhan yang dialami oleh pasien. Hasil pemeriksaan dokter akan dicatat dalam sebuah data yang disebut rekam medik beserta dengan diagnosa penyakit pasien, tindakan dokter, dan resep obat. Meskipun begitu, proses yang berjalan dalam klinik tidak hanya pemeriksaan kondisi tubuh pasien, tetapi juga Adminisitrasi klinik yang berguna untuk mendata segala bentuk kegiatan sesuai dengan proses bisnis yang berjalan, seperti pendaftaran pasien, pencatatan data obat, pemeriksaan pada laboratorium dan juga pembayaran obat. [1] Begitu pentingnya informasi bagi suatu pelayanan kesehatan termasuk klinik. Karena informasi yang cepat, tepat dan akurat akan memberikan hasil pelayanan terbaik bagi pasien 
yang melahirkan kepuasan pasien. penggunaan komputer akan membuat efektif dan efisien dalam melakukan pengolahan data. Pengolahan data yang dilakukan secara manual membutuhkan waktu yang lama meninbulkan ketidakvalidan data dan kerahasiaan data tidak bisa terjaga dengan baik. [2] klinik gigi membutuhkan sekali adanya suatu sistem informasi sebagai sarana promosi, pendaftaran dan perjanjian yang dapat menunjang dan memberikan pelayanan yang memuaskan bagi para pasien. mengenai pelayanan pasien yang berupa pendaftaran dan perjanjian di Klinik gigi yang sampai saat ini semua itu dilakukan secara manual. Untuk memecahkan permasalahan yang ada pada klinik ini, serta dengan sistem yang berbasis web ini dapat tercapai suatu kegiatan yang lebih efektif dalam menunjang aktifitas pendaftaran dan perjanjian pada klinik ini.

[3] informasi ini akan menyediakan data tentang pasien perawat, serta dokter yang akan memberikan pelayanan, pengelolaan sistem keuangan dan pembayaran, serta informasi dokumen yang dibutuhkan klinik gigi, penerapan sistem komputerisasi ini sangat diperlukan di tempat klinik, terutama berkaitan dengan pelayanan klinik yang diantaranya adalah pendaftaran, pemeriksaan, pembiayaan, dan pelaporan, semua data yang berkaitan dengan informasi pasien nantinya akan dicatat dan disimpan, sehingga dokumentasi pasien akan lebih teratur. [4] Sistem yang dirancang ini memiliki tujuan mengatur data yang ada pada klinik dengan media penyimpanan yang lebih praktis. Pada pasien bahasannya meliputi registrasi pasien baru dan pasien berobat, data rekam medis pasien, pemberian resep obat, perawatan, dan pembayaran.

Seperti halnya pada Dental Echo Clinic merupakan sebuah klinik yang bergerak dalam bidang jasa kesehatan gigi. Dilihat dari banyaknya pasien yang datang ke Dental Echo Clinic tersebut, Pada permasalahan waktu pelayanan dan validitas data, hal tersebut mutlak dilakukan untuk menjaga kualitas pelayanan yang baik. maka klinik gigi membutuhkan suatu sistem informasi yang sistematis dan terkomputerisasi, sehingga pelayanan terhadap pasien dapat menjadi lebih baik serta efektif. Pada proses penginputan data pasien, pencarian data pasien, rekam medis, proses pengolahan data administrasi pasien, dan pembuatan laporan masih menggunakan sistem informasi konvensional sehinga dapat memungkinkan terjadinya kesulitan bagi petugas untuk memberikan pelayanan yang efektif dan efesien terhadap pasien. Proses pembayaran pada Dental Echo Clinic masih terlihat kurang optimal. Terdapat banyak aspek yang merugikan bagi pasien, misalnya aspek pasien yang menunggu lama, data pasien tiba-tiba hilang sehingga mengisi data kembali, mencari data pasien yang masih manual, tidak tepat waktu dan kesalahan pembayaran.

Adapun batasan masalah penelitian ini
Pengguna dari sistem aplikasi pelayanan dental Echo clinic ini yaitu : Proses pendaftaran pasien agar data pasien dapat disimpan, Proses pendataan data diagnosa pasien agar disimpan dengan baik dan mudah untuk dicari, Proses pembayaran obat dan biaya pengobatan secara rinci agar diketahui rincian dari pembayaran obat tersebut, dan Pembuatan laporan pasien yang berobat perhari dan perbulan, data diagnosa pasien serta laporan pembayaran resep obat dan biaya pengobatan yang ada pada klinik gigi Echo. dan memproses data untuk menghasilkan informasi yang dapat membantu klinik dalam melakukan pelayanan kesehatan yang lebih baik lagi untuk masyarakat.

\section{Metode Penelitian}

Penelitian ini dilakukan dengan menggunakan metode kualitatif deskriptif. Pada penelitian ini mengambil objek mengenai sistem pelayanan yang berada di Dental Echo Clinic. Dengan pendekatan kualitatif dapat ditemukan data pelayanan kesehatan pada klinik gigi.

\section{A. Observasi}

Pengamatan langsung terhadap alur proses yang sedang berjalan dibagian pelayanan Dental Echo Clinic untuk memperoleh informasi yang nantinya akan diolah kedalam sistem informasi Klinik Gigi.

\section{B. Wawancara}

Kegiatan wawancara dilakukan dengan kepala 2dokter gigi dan 3 orang staff di Dental Echo Clinic beserta pihak - pihak yang terlibat dengan kegiatan penelitian.

\section{Studi Literatur}

Pengumpulan data dokumen secara langsung berupa form pendaftaran, kartu pasien, kwitansi pembayaran pasien, rekam medis, resep obat, dan surat keterangan sakit.

Metode pengembangan sistem yang digunakan adalah menggunakan metode WaterFall (Model Air Terjun). [5] Menurut Pressman (2015:42), model waterfall adalah model klasik yang bersifat sistematis, berurutan dalam membangun software.

Fase-fase dalam Waterfall Model menurut referensi Pressman :

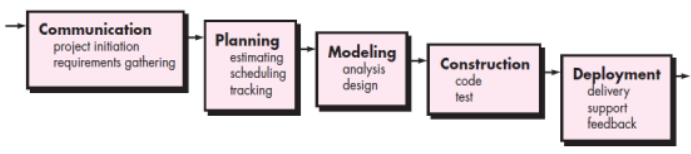

Gambar 1. Waterfall Pressman (Pressman, 2015:42)

\section{Communication (Project Initiation \& Requirements Gathering)}

Sebelum memulai pekerjaan yang bersifat teknis, sangat diperlukan adanya komunikasi 
dengan customer demi memahami dan mencapai tujuan yang ingin dicapai. Hasil dari komunikasi tersebut adalah inisialisasi proyek, seperti menganalisis permasalahan yang dihadapi dan mengumpulkan data-data yang diperlukan, serta membantu mendefinisikan fitur dan fungsi software. Pengumpulan datadata tambahan bisa juga diambil dari jurnal, artikel, dan internet.

2. Planning (Estimating, Scheduling, Tracking) Tahap berikutnya adalah tahapan perencanaan yang menjelaskan tentang estimasi tugas-tugas teknis yang akan dilakukan, resiko-resiko yang dapat terjadi, sumber daya yang diperlukan dalam membuat sistem, produk kerja yang ingin dihasilkan, penjadwalan kerja yang akan dilaksanakan, dan tracking proses pengerjaan sistem.

3. Modeling (Analysis \& Design)

Tahapan ini adalah tahap perancangan dan permodelan arsitektur sistem yang berfokus pada perancangan struktur data, arsitektur software, tampilan interface, dan algoritma program. tujuannya untuk lebih memahami gambaran besar dari apa yang ingin dikerjakan.

4. Construction (Code \& Test)

Tahapan Construction ini merupakan proses penerjemahan bentuk desain menjadi kode atau bentuk/bahasa yang dapat dibaca oleh mesin. Setelah pengkodean selesai, dilakukan pengujian terhadap sistem dan juga kode yang sudah dibuat. Tujuannya untuk menemukan kesalahan yang mungkin terjadi untuk nantinya diperbaiki.

5. Deployment (Delivery, Support, Feedback)

Tahapan Deployment merupakan tahapan implementasi software ke customer, pemeliharaan software secara berkala, perbaikan software, evaluasi software, dan pengembangan software berdasarkan umpan balik yang diberikan agar sistem dapat tetap berjalan dan berkembang sesuai dengan fungsinya. (Pressman, 2015:17)

Pada tahap analisa sistem pada penelitian ini melakukan analisa menggunakan metode Analisa SWOT (Strenghts, Weaknesses, Opportunities, Threats). Analisis SWOT merupakan teknik analisa yang membantu menentukan cara terbaik bagi perusahaan untuk mencapai tujuan, baik dalam hal servis, produk maupun pemasaran. Pelaksanaan analisa SWOT akan membantu sebuah perusahaan dalam menentukan segmen pasar yang menawarkan peluang terbaik untuk mencapai kesuksesan sehingga perusahaan dapat mencapai profit yang diharapkan dari produk yang telah dihasilkan. [6] [Tim FME.2013].

\section{Kekuatan (Strength)}

Merupakan faktor internal yang bersifat positif dan mendukung untuk mencapai tujuan dari sebuah perusahaan. Strength memberikan keunggulan bagi suatu perusahaan dibandingkan kompetitornya. Strength mencakup kekayaan perusahaan, aset, reputasi, klient yang loyal, karyawan yang ahli dan aspek-aspek yang berharga lainnya dalam sebuah perusahaan.

2. Kelemahan (Weakness)

Merupakan faktor internal yang menjadi titik kekurangan sebuah perusahaan dalam mencapai tujuannya. Dengan adanya weakness maka perusahaan dapat mendefinisikan kelemahan apa saja yang dimiliki sehingga menyebabkan sebuah perusahaan kalah saing dengan kompetitor. Weakness juga dapat menentukan servis maupun performa dari perusahaan apa saja yang kurang disukai oleh klien.

3. Peluang (Opportunity)

Merupakan faktor eksternal yang berpengaruh untuk meningkatkan kemungkinan sebuah perusahaan dalam mencapai tujuan. Opportunity dapat mempengaruhi keberlangsungan sebuah perusahaan di masa mendatang. Opportunity berasal dari perubahan pasar, perubahan pola hidup komsumen, perkembangan teknologi, berbagai macam metode produksi yang baru, dan lain sebagainya.

4. Ancaman (Threat)

Merupakan faktor eksternal yang bersifat negatif dan dapat menambah resiko sebuah perusahaan dalam mencapai fungsi dan tujuannya. Resiko tersebut merupakan ancaman yang berasal dari faktor eksternal dan berada di luar kontrol suatu perusahaan. Walaupun Threat merupakan faktor eksternal, perusahaan harus tetap mempertimbangkan untuk membuat rencana antisipasi apabila hal yang buruk terjadi. Semakin proaktif sebuah perusahaan dalam mengidentifikasi ancaman terhadap perusahaan, maka akan semakin baik bagi keberlangsungan perusahaan dimasa mendatang.

Tahapan yang dilakukan dalam penelitian ini adalah sebagai berikut: 


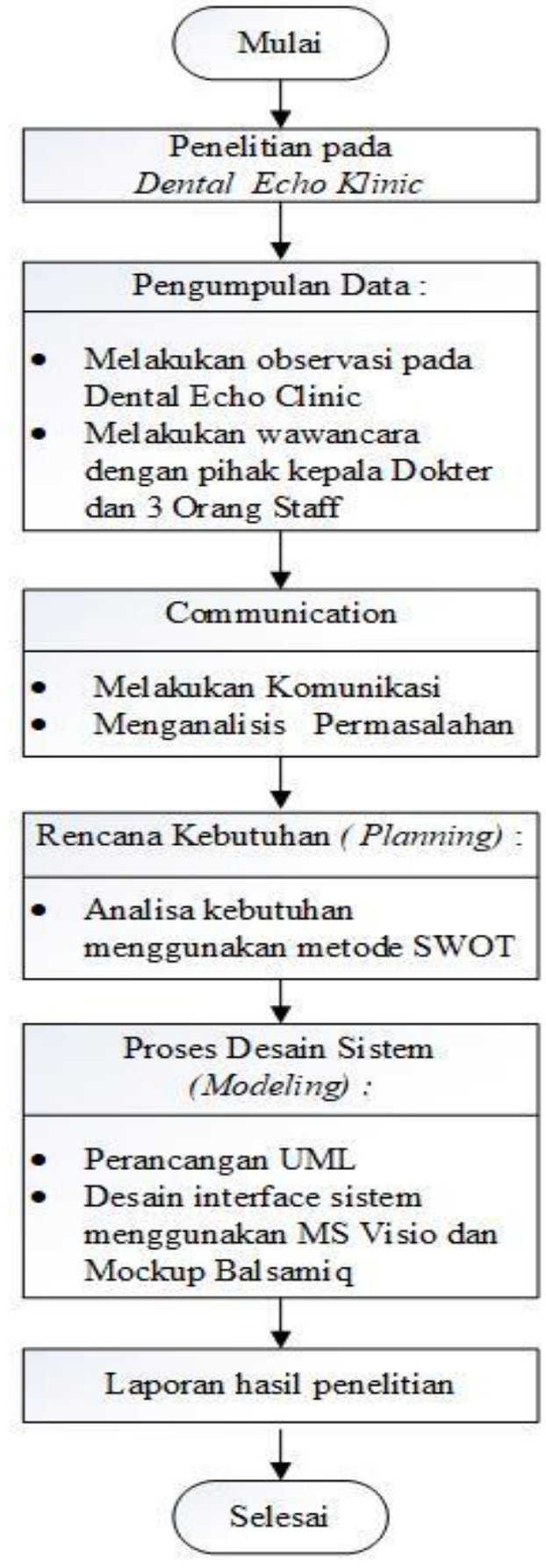

Gambar 2. Diagram Alur Penelitian

\section{Hasil Dan Pembahasan}

\subsection{Rencana Kebutuhan \\ Planning) \\ (Requirement}

Pada tahap ini dilakukan analisa kebutuhan sistem informasi pelayanan klinik gigi pada Dental Echo Clinic untuk merencanakan kebutuhan yang tepat, mengidentifikasi masalah dan memberikan solusi terhadap permasalahan yang dihadapi selama ini.
1. Proses Sistem Berjalan pelayanan pada Dental Echo Clinic

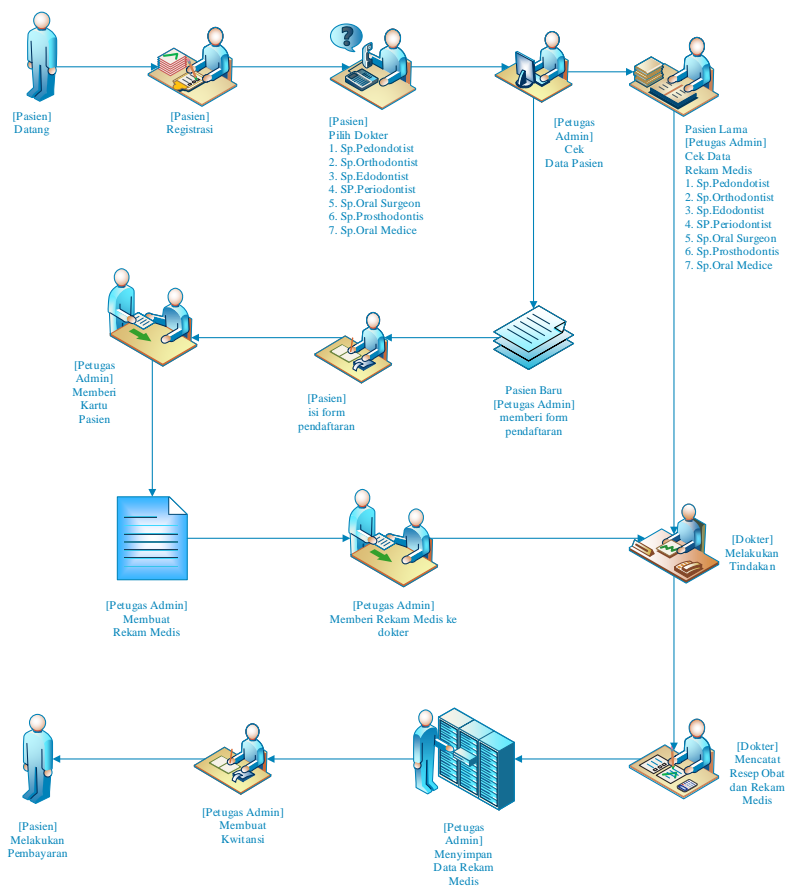

Gambar 3. Flowchart Proses Sistem Berjalan Dental Echo Clinic

Alur proses sistem berjalan pelayanan pada Dental Echo Clinic yaitu:

- Pasien melakukan pendaftaran ke Dental Echo Clinic.

- $\quad$ Pasien pilih dokter spesialis

- Petugas admin mengecek data pasien. Jika pasien lama :

- petugas admin mencari data rekam medis pasien lama sesuai spesialis data rekam medis.

- Selanjutnya form rekam medis diberikan ke dokter.

- Dokter melakukan tindakan, lalu dokter mencatat data dalam rekam medis dan membuat resep untuk pasien.

- Selanjutnya form rekam medis dan form resep dokter diberikan ke petugas admin.

- Selanjutnnya petugas admin membuat kwitansi pembayaran.

- Form rekam medis disimpan diarsip oleh petugas admin.

- $\quad$ Petugas admin memberikan form resep dokter dan kwitansi kepada pasien.

- Pasien menerima form resep dokter dan kwitansi.

- Pasien melakukan pembayaran.

Jika pasien baru : 
- $\quad$ Petugas admin memberikan form pendaftaran kepada pasien.

- Pasien menerima form pendaftaran dan mengisi form pendaftaran lalu diberikan kepada petugas admin.

- $\quad$ Form pendaftaran diterima oleh admin.

- Selanjutnya petugas admin membuat kartu pasien.

- Pasien menerima kartu pasien.

- Petugas admin membuat form rekam medis dan form tersebut diberikan ke dokter.

- Dokter melakukan tindakan, lalu dokter mencatat data dalam rekam medis dan membuat resep untuk pasien.

- Selanjutnya form rekam medis dan form resep dokter diberikan ke petugas admin.

- $\quad$ Selanjutnnya petugas admin membuat kwitansi pembayaran.

- Form rekam medis disimpan diarsip oleh petugas admin.

- $\quad$ Petugas admin memberikan form resep dokter dan kwitansi kepada pasien.

- Pasien menerima form resep dokter dan kwitansi.

- $\quad$ Pasien melakukan pembayaran.

\subsection{Analisa SWOT}

Dari hasil wawancara yang dilakukan oleh peneliti dengan kepala dokter dan 3 orang staff, Peneliti menggunakan metode SWOT (Strengths, Weaknesses, Opportunities, Threats) untuk melihat kekuatan, kelemahan, peluang serta ancaman dari sistem yang selama ini dijalankan.

\section{Analisa Sistem SWOT}

\section{Strengths (S)}

1. Adanya dukungan dari klinik gigi Echo.

2. Struktur petugas pelayanan klinik gigi yang jelas.

3. Pelayanan sesuai SPO.

4. Tarif pelayanan sudah sesuai.

\section{Weakneses $(\mathbf{W})$}

1. Kesulitan mencari data Arsip

2. Pencatatan menggunakan kertas.

3. Pencarian data pasien membutuhkan waktu lama

4. Data arsip mudah hilang dan rusak.

5. Sarana prasarana klinik gigi masih kurang memadai dan kurang upgrade.

Opportunies (O)

1. Meningkatkan kepuasan kerja karyawan.

2. Meningkatkan Pelayanan mutu.

3. Keberadaan klinik gigi sangat dibutuhkan masyarakat.

\section{Strategi (SO)}

1. Membuat master data pengguna untuk mempermudah proses kinerja karyawan.

2. Membuat data antrian untuk mempercepat proses pelayanan terhadap pasien.

3. Membuat data layanan untuk melihat informasi jenis layanan beserta biaya dalam setiap pelayanan.

\section{Strategi (WO)}

1. Membuat data pencarian rekam medis pasien sesuai dengan nama sehingga mempercepat proses kinerja karyawan dalam mencari data rekam medis.

2. Membuat form data pasien yang dapat terintegrasi antara data pasien dengan data pendaftar.

3. Membuat form rekam medis dan form resep dokter untuk mencatat hasil diagnosa dokter.

Threaths (T)

1. Hasil laporan data pelayanan diklinik kurang optimal.

2. Klinik gigi lain diwilayah sekitar klinik sudah memiliki fasilitas yang lebih memadai.

\section{Strategi (ST)}

1. Membuat data laporan master data klinik gigi dari klinik tersebut untuk membantu menganalisa tingkat efektivitas operasional di klinik tersebut.

\section{Strategi (WT)}

1. Membuat data laporan pasien yang berobat ke klinik sehingga bisa dijadikan bahan oleh manajemen untuk menganalisa tingkat pelayanan klinik tersebut.

2. Melakukan upgrading sarana dan prasarana sehingga fasilitas di klinik gigi dapat bersaing dengan klinik gigi lain disekitarnya yang memiliki fasilitas yang lebih memadai.

\subsection{Proses Desain Sistem (Design System)}




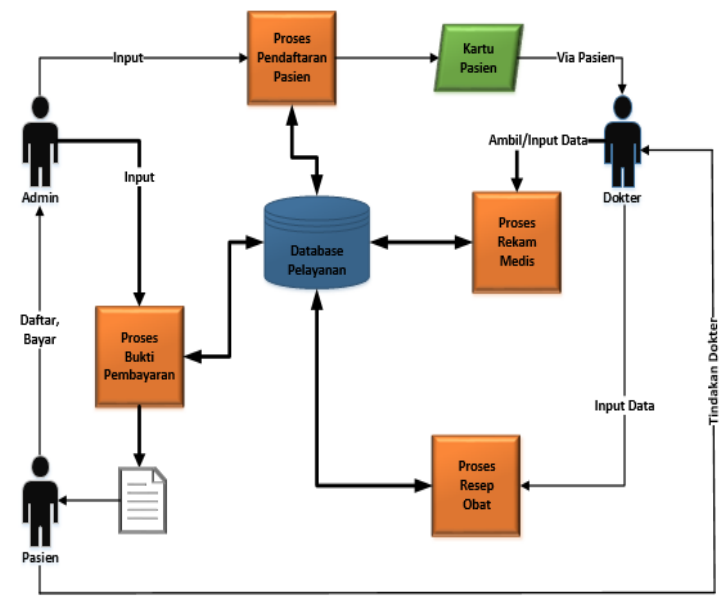

\section{Perancangan Antar Muka}

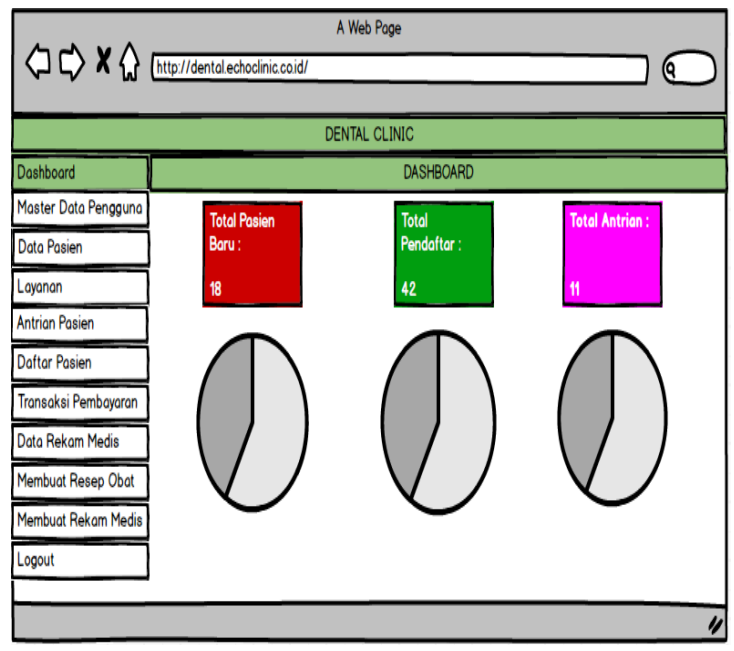

Gambar 4. Tampilan Halaman Dashboard

Gambar 4 di atas merupakan tampilan utama dari aplikasi setelah user berhasil memasukkan sandi dengan benar pada halaman login.

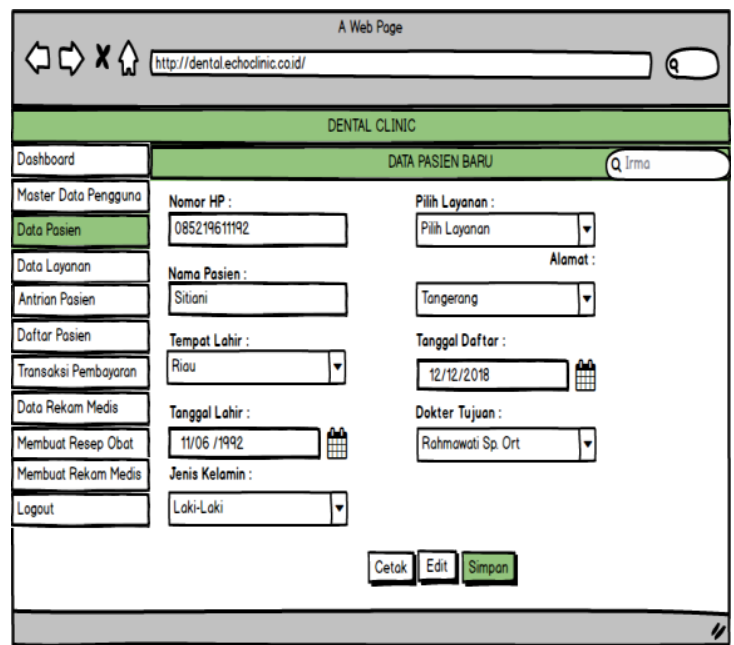

Gambar 5. Tampilan Form Input Data Pasien Baru

Gambar 5 di atas merupakan form untuk menginput data pasien baru kemudian petugas admin menginput data pasien baru, terdiri dari nomor $\mathrm{hp}$, nama pasien, tempat lahir, tanggal lahir, jenis kelamin, plih layanan, alamat, dan dokter tujuan, lalu mengklik tombol simpan lalu sistem akan menyimpan data pasien baru jika data sesuai maka sistem akan menampilkan data yang telah tersimpan dan data pasien baru otomatis tersimpan ke daftar pasien.

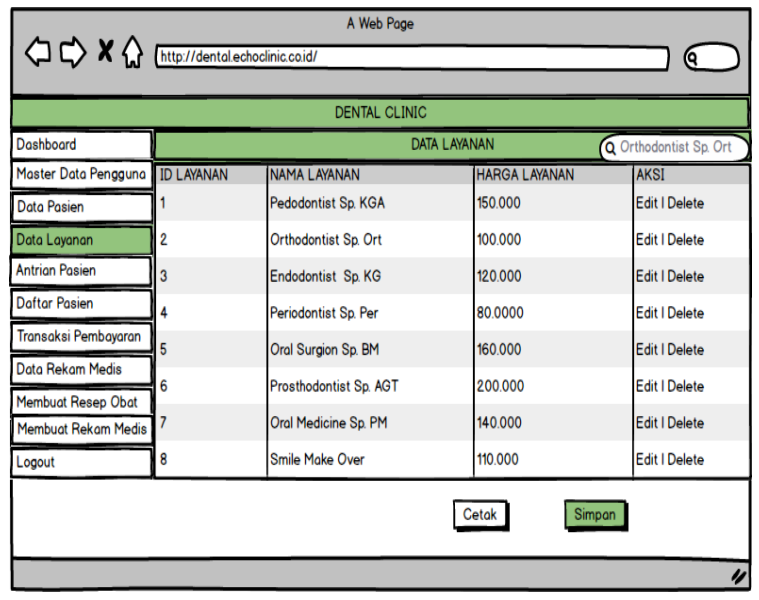

Gambar 6. Tampilan Data Layanan

Gambar 6 di atas merupakan tampilan Data Layanan petugas admin melakukan pencarian data layanan, kemudian sistem menampilkan data pencarian layanan, petugas admin menginput data layanan sesuai nama lalu mengklik tombol search kemudian sistem menampilkan data layanan yang dicari.

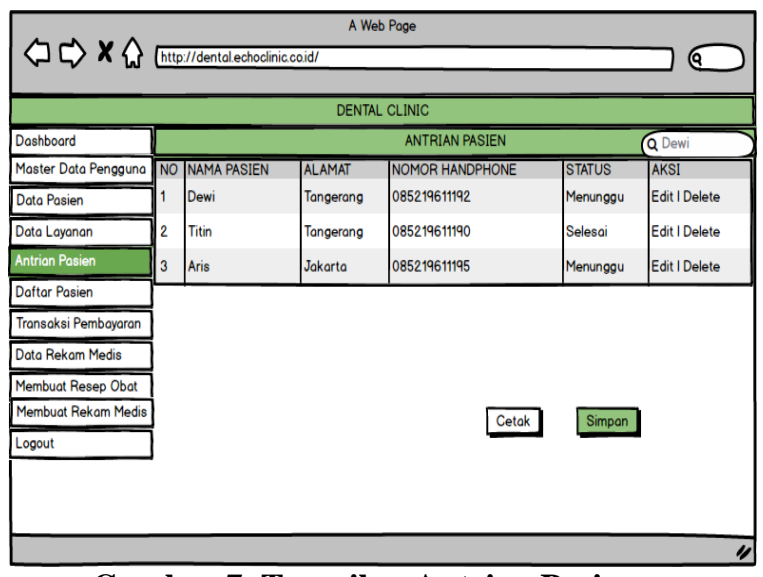

Gambar 7. Tampilan Antrian Pasien

Gambar 7 di atas merupakan tampilan antrian pasien, petugas admin melakukan aksi edit dan delete dan dapat melakukan pencarian data antrian setelah petugas admin menginput data antrian berdasarkan nama pasien lalu mengklik tombol search kemudian sistem menampilkan data antrian yang dicari, petugas admin dapat mencetak laporan antrian pasien kemudian sistem akan menampilkan data laporan antrian pasien yang akan dicetak. 


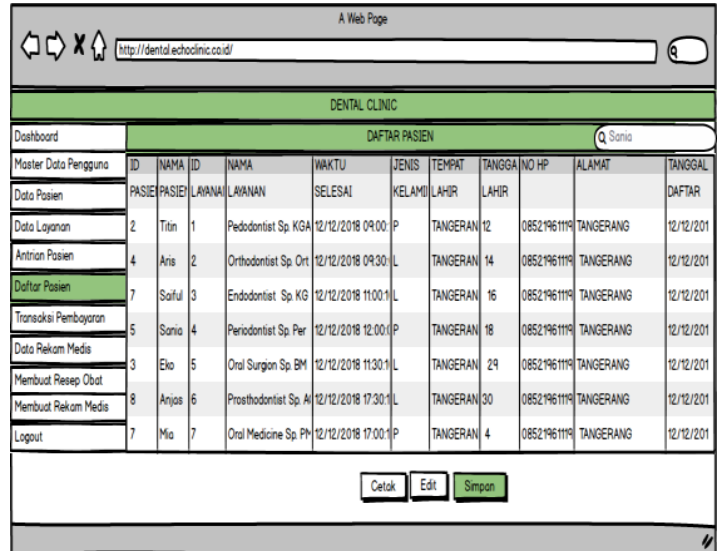

Gambar 8. Tampilan Laporan Daftar Pasien Gambar 8 di atas merupakan tampilan laporan daftar pasien, terdiri dari id pasien, nama pasien, id layanan, nama layanan, waktu selesai, jenis kelamin, tempat lahir, tanggal lahir, no hp, alamat dan tanggal daftar. Dan petugas admin dapat melakukan pencarian data pasien setelah petugas admin menginput data pasien berdasarkan nama pasien lalu mengklik tombol search kemudian sistem menampilkan data pasien yang dicari, petugas admin dapat mencetak laporan data pasien kemudian sistem akan menampilkan data laporan pasien yang akan dicetak.

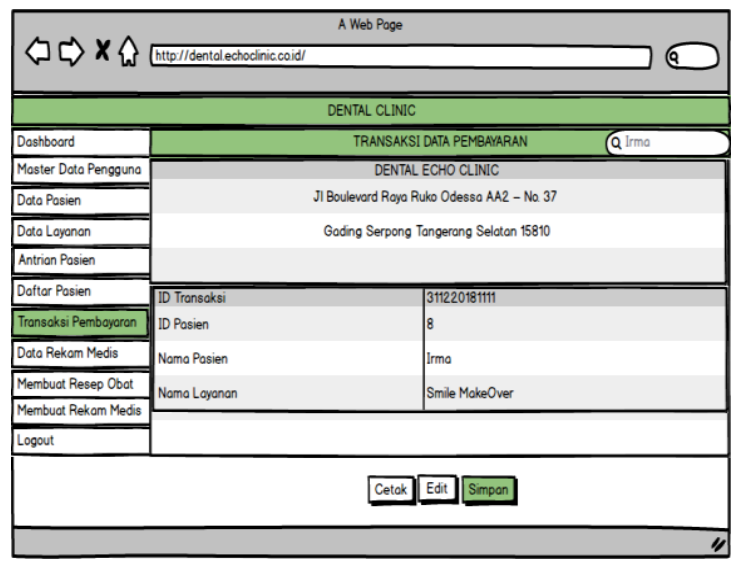

Gambar 9. Tampilan Transaksi Pembayaran Pasien

Gambar 9 di atas merupakan tampilan transaksi data pembayaran pasien yanng terdiri dari id transaksi, id pasien, nama pasien, dan nama layanan.

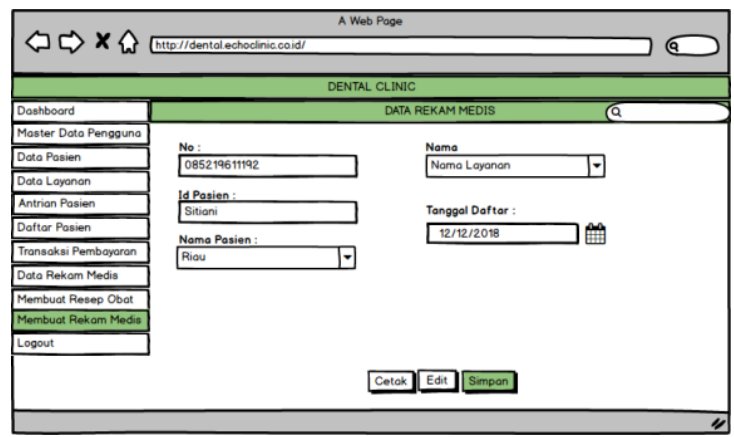

Gambar 10. Tampilan Form Data Rekam Medis
Gambar 10 di atas merupakan tampilan form data rekam medis yang terdiri dari no, id pasien, nama pasien, nama layanan, dan tanggal daftar.

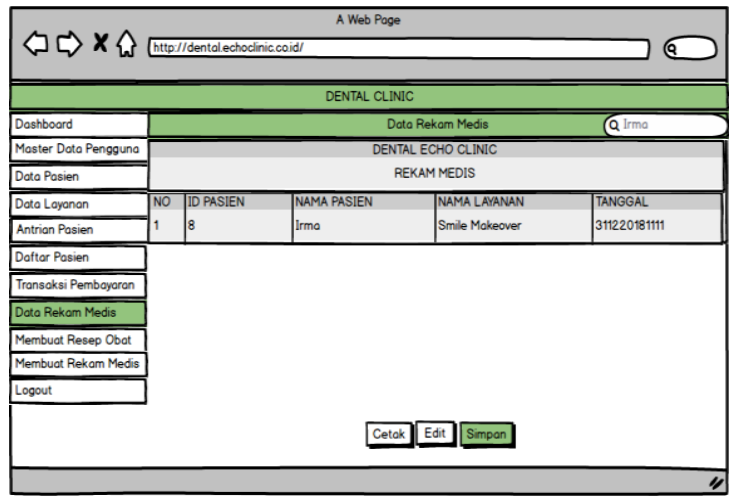

Gambar 11. Tampilan Data Rekam Medis

Gambar 11 di atas merupakan tampilan data rekam medis yang terdiri dari no, id pasien, nama pasien, nama layanan, dan tanggal.

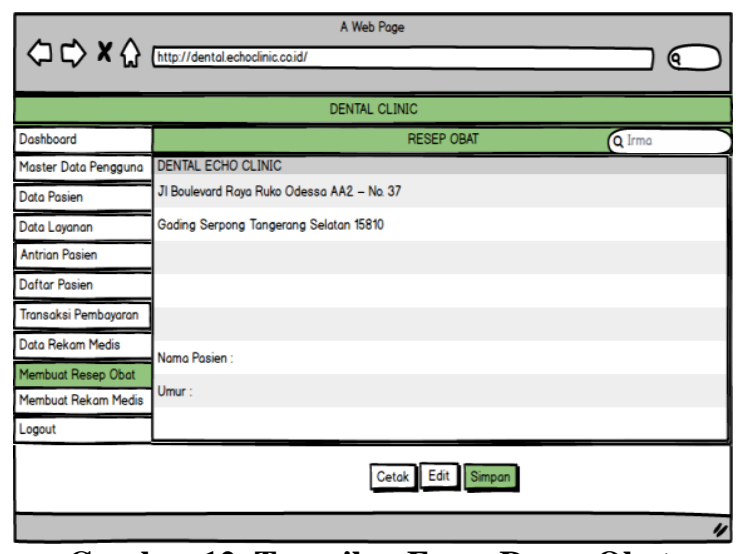

Gambar 12. Tampilan Form Resep Obat

Gambar 12 di atas merupakan tampilan form resep obat yang terdiri dari nama pasien, umur dan resep yang telah diberikan oleh dokter.

\section{Kesimpulan}

Berdasarkan penelitian yang telah dilakukan, maka dapat ditarik kesimpulan yaitu dengan adanya Perancangan Aplikasi Sistem Pelayanan Klinik Gigi yang dapat mempermudah proses pelayanan, membantu meningkatkan efektivitas waktu dalam proses pelayanan klinik gigi di Dental Echo Clinic, meningkatkan efisiensi sistem pencatatan dalam pelayanan klinik gigi secara cepat dan akurat. Serta Perancangan sistem ini dapat membantu meminimalisir kerugian atas terjadinya kesalahan pencatatan data pasien.

\section{Referensi}

[1] Apriliyani, Aini Inayati \& Febbi Dea Fauzi.2018. Desain Database Sistem Informasi Rekam Medis Berbasis Microsoft Access Di Klinik Dokter Gigi. Jurnal Hospital Science.ISSN: 2598-0122 (online); 25980114. 
[2] Rodiana,Nur, Fajar Akbar \& Asep Sayfulloh.2017. RancangBangun Sistem Informasi Pelayanan Pasien Berbasis Web pada Klinik Gigi Lily Jakarta Barat. Simposium Nasional Ilmu Pengetahuan dan Teknologi (SIMNASIPTEK).ISBN: 978-60261268-4-9

[3] Puspita Sari,Ira \& Diki Arisandi. 2017. Sistem Informasi Manajemen Klinik Gigi Berbasis Client Server (Studi Kasus Poliklinik Gigi Rsj Tampan, Pekanbaru). Jurnal Teknologi dan Sistem Informasi VOL. 2 No.1. ISSN CETAK : 2477-2062, ISSN ONLINE : 2502$891 X$.

[4] Kumara Micelia Propa, Andy Prasetyo Utomo, Fajar Nugraha .2015. Sistem Informasi Manajemen Klinik Permata Medical Center Pati. Prosiding SNATIF Ke-2 Tahun 2015: ISBN : 978-602-1180-21-1.

[5] Pressman, R.2015. Rekayasa Perangkat Lunak: Pendekatan Praktisi Buku 1. Yogyakarta: ANDI.

[6] Team FME. 2013. SWOT Analysis, Strategy Skills SWOT Analysis www.freemanagement-ebooks.com ISBN 978-1-62620951-0. 